\title{
QUALIDADE FISIOLÓGICA, SANITÁRIA E TRANSMISSÃO DE PATÓGENOS EM SEMENTES DE CANOLA
}

Patricia Migliorini ${ }^{1}$, Marília Lazarotto ${ }^{2}$, Jucéli Müller ${ }^{3}$, Pâmela Oruoski ${ }^{3}$, Marcieli Pitorini Bovolini ${ }^{2}$, Marcieli Barbieri ${ }^{2}$, Lilian Vanussa Madruga de Tunes ${ }^{1}$, Marlove Fátima Brião Muniz ${ }^{2}$

${ }^{1}$ Universidade Federal de Pelotas - UFPEL, Programa de Pós-Graduação em Ciência \& Tecnologia de Sementes, Pelotas, RS. ${ }^{2}$ Universidade Federal do Rio Grande do Sul - UFRGS. ${ }^{3}$ Universidade Federal de Santa Maria - UFSM. Email: pati.migliorini@gmail.com

\section{RESUMO}

A utilização de sementes com bom potencial fisiológico e sanitário garante no início do desenvolvimento da cultura um estande de plântulas adequadas que consequentemente poderá levar a bons níveis de produtividade e qualidade das lavouras. Objetivou-se com este trabalho avaliar a qualidade das sementes de canola, através dos atributos fisiológicos, sanitários e de transmissão de patógenos. Foram avaliados três cultivares de sementes de canola (Hyola 401, Hyola 61 e Hyola 60) produzida em Santa Maria, Rio Grande do Sul. As sementes foram avaliadas pelo peso de mil sementes, teor de água, germinação, comprimento total de plântulas, condutividade elétrica, emergência, índice de velocidade de emergência, sanidade e transmissão de fungos via semente. O delineamento experimental utilizado foi o inteiramente casualizado com oito repetições. De acordo com os testes realizados observou-se que a germinação, comprimento total de plântulas, condutividade elétrica e índice de velocidade de emergência permitem a diferenciação das cultivares de canola. Os fungos encontrados nas sementes foram Alternaria alternata, $A$. brassicicola, A. japonica, Fusarium spp., Phoma lingam, Aspergillus flavus, Penicillium spp., Botrytis spp. e Rhizopus spp., mas somente $A$. alternata, $A$. brassicicola e $P$. lingam são transmitidos para as plântulas de canola quando associados as suas sementes, causando danos em pré e pós-emergência.

Palavras-chave: Brassica napus L. var. oleifera Metzg.; germinação; sanidade de sementes; vigor.

\section{PHYSIOLOGICAL, SANITARY QUALITY AND TRANSMISSION OF PATHOGENS IN CANOLA SEEDS}

\begin{abstract}
The use of seeds with good physiological and sanitary potential guarantees, at the beginning of the development of the crop, a stand of suitable seedlings that consequently can lead to good levels of productivity and quality of the crops. The objective of this work was to evaluate the quality of canola seeds, through the physiological, sanitary and pathogen transmission characteristics. Three cultivars of canola seeds (Hyola 401, Hyola 61 and Hyola 60) were evaluated in Santa Maria, Rio Grande do Sul. Seeds were evaluated by weight of one thousand seeds, water content, germination, total length of seedlings, conductivity emergency speed index, sanity and transmission of fungi via seed. The experimental design was a completely randomized design with eight replicates. According to the tests carried out, it was observed that germination, total seedling length, electrical conductivity and speed index of emergence allow the differentiation of canola cultivars. The fungi found in the seeds were Alternaria alternata, $A$. brassicicola, A. japonica, Fusarium spp., Phoma lingam, Aspergillus flavus, Penicillium spp., Botrytis spp. and Rhizopus spp., but only A. alternata, $A$. brassicicola and $P$. lingam are transmitted to the canola seedlings when associated with their seeds, causing damage before and after emergence.
\end{abstract}

Keywords: Brassica napus L. var. oleifera Metzg; germination; seeds health; vigor.

\section{INTRODUÇÃO}

$\mathrm{Na}$ busca de fontes renováveis para suprir a produção de biodiesel, a canola (Brassica napus L. var. oleifera Metzg.) tem se destacado nos últimos anos, pela considerável importância como matéria prima, por possuir elevado teor de óleo, propriedades físicas e químicas que realçam a qualidade do produto final, além de contribuir 
na geração de renda para os agricultores durante o inverno (TOMM, 2009). Além disso, a canola é a terceira oleaginosa mais produzida no mundo. Trata-se de uma planta anual, herbácea, pertencente à família das Brassicacea e que produz grãos ricos em óleo de excelente qualidade (ESTEVEZ et al., 2014).

No mercado de sementes, há uma oferta crescente de materiais cada vez mais produtivos e adaptados às condições locais, principalmente pelo avanço dos programas de melhoramento genético nacional e internacional, o que é revertido em grande diversidade de benefícios aos produtores. Contudo, o sucesso do estabelecimento e desempenho de uma cultura depende da qualidade das suas sementes, fator que está diretamente relacionado com altas taxas de germinação, de vigor e de sanidade, bem como a garantia da pureza física e genética (CARVALHO; NAKAGAWA, 2012). Deste modo, informações sobre a qualidade das sementes de canola são necessárias a fim de assegurar plantios uniformes e livres de doenças.

Lotes e cultivares de sementes podem apresentar desempenhos diferentes no campo e em laboratório, tornando-se necessária a realização de vários testes para avaliar a qualidade desse material. $O$ teste de germinação permite que as sementes expressem seu máximo potencial germinativo, pois proporciona condições ótimas de ambiente, controladas e padronizadas (MARCOS FILHO, 2015). Já, os testes de vigor não são padronizados e nem reconhecidos pelas Regras de Análise de Sementes (BRASIL, 2009), no entanto, eles complementam informações obtidas no teste de germinação e geralmente são utilizados para o controle interno das empresas produtoras de sementes. Pois se sabe que sementes vigorosas influenciam o desempenho inicial das plantas, proporcionando uma emergência rápida e uniforme sob ampla variação de ambiente (MARCOS FILHO, 2015).

Organismos fitopatogênicos podem ser transportados pelas sementes, embora a transmissão de inúmeros deles não seja totalmente conhecida (ARAÚJO, 2008). Mas a constatação da presença de microrganismos na semente, não é suficiente para garantir que estes irão infectar a planta proveniente dessa semente, porém a associação patógeno-semente indica um meio potencial de transmissão e possível estabelecimento da doença no campo podendo se tornar ativos, assim que encontrarem condições favoráveis para o seu desenvolvimento, os danos podem variar desde tombamento de pré e pós emergência, podridão radicular, manchas necróticas em folhas e hastes, descoloração de tecidos e infecções latentes (NEERGAARD, 1979; MARINO et al., 2008).

A transmissão de microrganismos através das sementes pode ocorrer pela presença de esporos, estruturas de sobrevivência ou resíduos de colheita (CARVALHO; NAKAGAWA, 2012). Além da localização do patógeno na semente a qualidade e o tipo de inóculo, assim como os fatores ambientais (temperatura e umidade), também influenciam na capacidade de transmissão, sendo geralmente os patógenos que se localizam no embrião da semente facilmente transmitido para as plântulas. Desta forma, conhecer a dinâmica de transmissão de patógenos por sementes, se torna importante já que estes apresentam diferentes formas de estar veiculados em um lote, especialmente para culturas que possuem informações escassas, como é o caso da canola, pois um mesmo patógeno pode estar presente em um lote, ou em uma semente, sob uma ou mais formas de localização (MACHADO, 2012).

O presente trabalho teve por objetivo avaliar a qualidade fisiológica e sanitária, incluindo a transmissão de fungos de sementes de canola.

\section{MATERIAL E MÉTODOS}

O trabalho foi desenvolvido no Laboratório de Fitopatologia do Departamento de Defesa Fitossanitária (DFS) da Universidade Federal de Santa Maria (UFSM), Santa Maria - RS.

Foram utilizadas sementes das cultivares de canola: Hyola 401, Hyola 61 e Hyola 60, cultivadas em Santa Maria e classificada em peneiras de tamanho de $2 \mathrm{~mm}$, da safra de 2012, oriundas da área experimental do DFS, que está situada na Depressão Central do Rio Grande do Sul, com coordenadas de latitude 29o 43' 04 Sul e longitude de 53 43' 01 Oeste e altitude de 116 metros. O solo é classificado como um Argissolo Vermelho distrófico arênico, com terreno de topografia plana (EMBRAPA, 1999). O clima da região segundo Köppen, pertence ao tipo $\mathrm{Cfa}$, subtropical úmido com verões quentes e sem estação seca definida (HELDWEIN et al., 2009).

Os tratamentos foram compostos por três cultivares e oito repetições, conduzidos em delineamento inteiramente casualizado e avaliados através dos seguintes testes: 
Teor de água das sementes: determinado através do método da estufa $105 \pm 2{ }^{\circ} \mathrm{C}$, conforme as Regras para Análises de Sementes (BRASIL, 2009).

Peso de mil sementes: efetuado de acordo com as Regras para Análise de Sementes (BRASIL, 2009) por meio de oito sub-amostras de 100 sementes em cada repetição de cada tratamento.

Teste de germinação: foram utilizadas oito repetições de 50 sementes, para cada tratamento, utilizando-se como substrato o rolo de papel tipo Germitest ${ }^{\circ}$, umedecido com água destilada na proporção de 2,5 vezes seu peso seco. Após a confecção dos rolos, estes foram embalados em sacos plásticos e mantidos em câmara de germinação (B.O.D), à $25 \pm 2^{\circ} \mathrm{C}$ e fotoperíodo de $12 \mathrm{~h}$ de luz. As contagens foram realizadas no quarto e sétimo dia após a instalação do teste e os resultados expressos em porcentagem de plântulas normais (BRASIL, 2009).

Comprimento total de plântulas: conduzido similarmente como no teste de germinação, sendo avaliado no sétimo dia após a montagem do teste, com quatro sub-amostras de 10 plântulas para cada tratamento, as quais foram escolhidas aleatoriamente a partir da semeadura de 20 sementes por repetição no terço superior da folha de papel Germitest ${ }^{\bullet}$. A determinação foi realizada com auxílio de uma régua milimetrada, e os resultados foram expressos em cm. plântula ${ }^{-1}$.

Teste de condutividade elétrica: realizado conforme a metodologia descrita por Marcos Filho (2015), sendo utilizado oito repetições de 50 sementes por tratamento. A massa das sementes foi aferida através de balança analítica com precisão de $0,01 \mathrm{~g}$, posteriormente, as sementes foram colocadas em copos plásticos contendo $25 \mathrm{~mL}$ de água destilada e mantidas à $25^{\circ} \mathrm{C}$ por $24 \mathrm{~h}$. Após este período, foi realizada a leitura da condutividade elétrica em condutívimetro digital (modelo BEL W 12-D), sendo os resultados expressos em $\mu \mathrm{Scm}^{-1} \mathrm{~g}^{-1}$ de semente.

Emergência: foram semeadas oito repetições de 25 sementes por tratamento, em bandejas plásticas contendo substrato comercial (marca Carolina Soil ${ }^{\circ}$ ) esterilizado em autoclave

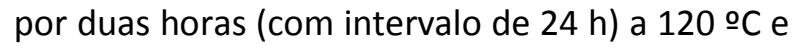
1 atm. O material permaneceu em sala climatizada a $25 \pm 2$ o $\mathrm{C}$ e fotoperíodo de $12 \mathrm{~h}$, com irrigação manual, próximo à capacidade de campo. A avaliação foi realizada aos 21 dias após a semeadura, computando-se em porcentagem (\%), as plântulas normais emergidas.

Índice de velocidade de emergência: realizado conjuntamente com o teste de emergência, no qual foram realizadas contagens diárias das plântulas emergidas até a estabilização. Para cada repetição, foi aplicada a fórmula de Maguire (1962): IVE $=E_{1} / N_{1}+E_{2} / N_{2}+$ $\ldots+\mathrm{En} / \mathrm{Nn}$, onde: IVE = índice de velocidade de emergência; $E_{1}, E_{2}$, En = número de plântulas normais computadas na primeira, segunda e última contagem e $\mathrm{N}_{1}, \mathrm{~N}_{2}, \mathrm{Nn}=$ número de dias entre a semeadura e a primeira, segunda e última contagem.

Teste de sanidade: realizado por meio do método de papel de filtro ou "Blotter test" com congelamento (BRASIL, 2009). Com oito repetições de 50 sementes acondicionadas em caixas tipo gerbox, contendo três folhas de papel Germitest , previamente umedecidas com água destilada e esterilizada. Incubados por sete dias à temperatura de $25 \pm 2$ 으, sob fotoperíodo de 12 h. As estruturas dos fungos associadas às sementes foram observadas sob microscópio estereoscópico e ótico e comparadas com estruturas descritas por Barnett e Hunter (1998) e as espécies de Alternaria por Simmons (2007). Os resultados foram expressos em porcentagem (\%) de incidência.

Teste de transmissão: realizado conjuntamente com o teste de emergência de plântulas. A avaliação foi efetuada aos 21 dias após a semeadura, quando foram avaliadas as plântulas com sintomas e as sementes mortas. Considerou-se como plântulas com sintomas de doenças aquelas que apresentavam qualquer mancha necrótica na região do colo. Estas foram então retiradas e colocadas em câmara úmida por sete dias, para a identificação dos patógenos presentes. A câmara úmida foi realizada em caixas gerbox previamente desinfestadas com álcool $70 \%$ e hipoclorito de sódio a $1 \%$, contendo três folhas de papel filtro umedecido com água destilada e esterilizada.

Análise estatística dos dados: as médias dos tratamentos foram comparadas pelo teste de Tukey $(p \leq 0,05)$ e os dados não-normais (porcentagem) foram transformados segundo arc sen $\mathrm{V} x / 100$. Posteriormente, determinou-se 0 coeficiente de correlação simples de Pearson ( $r$ ) para as combinações de qualidade fisiológica.

\section{RESULTADOS E DISCUSSÃO}


Observa-se que houve diferença significativa entre os tratamentos para as variáveis de teor de água (TA), peso de mil sementes (PMS), germinação (G), comprimento total de plântulas (CTP), condutividade elétrica (CE) e índice de velocidade de emergência (IVE) (Tabela 1).

O teor de água das sementes variou entre $5,3 \%$ e $6 \%$ para o Hyola 401 e Hyola 61 , os quais não diferiram significativamente do Hyola 60 (5 $\%)$ (Tabela 1). Resultados semelhantes foram obtidos por Ávila et al. (2005) em sementes dessa mesma cultura. Santos et al. (2012), concluíram que o teor de água das sementes de canola não influencia $o$ processo germinativo, pois geralmente sementes que apresentam baixo teor de água resultam em um maior número de plântulas anormais e de menor vigor, devido principalmente a embebição acelerada durante o processo de germinação, o que ocasiona desorganização da membrana celular e rupturas dos tecidos (POWELL; MATTHEWS, 1978), no entanto, esses efeitos negativos não foram observados durante a germinação e o vigor das sementes de canola.

Tabela 1. Qualidade física e fisiológica de sementes de canola das cultivares Hyola 401, Hyola 61 e Hyola 60, safra 2012, cultivadas em Santa Maria, RS

\begin{tabular}{llllllll}
\hline Tratamento & TA $(\%)$ & PMS $(\mathrm{g})$ & $\mathrm{G}(\%)$ & $\mathrm{CTP}(\mathrm{cm})$ & $\mathrm{CE}\left(\mu \mathrm{cm}^{-1} \mathrm{~g}^{-1}\right)$ & $\mathrm{E}(\%)$ & $\mathrm{IVE}$ \\
\hline Hyola 401 & $5,3 \mathrm{~b}^{*}$ & $4,6 \mathrm{a}$ & $75 \mathrm{~b}$ & $10,6 \mathrm{~b}$ & $109,0 \mathrm{ab}$ & $94 \mathrm{a}$ & $5 \mathrm{~b}$ \\
Hyola 61 & $6,0 \mathrm{a}$ & $4,3 \mathrm{~b}$ & $88 \mathrm{a}$ & $12,2 \mathrm{a}$ & $124,1 \mathrm{a}$ & $92 \mathrm{a}$ & $5 \mathrm{~b}$ \\
Hyola 60 & $5,0 \mathrm{ab}$ & $4,7 \mathrm{a}$ & $86 \mathrm{a}$ & $12,5 \mathrm{a}$ & $96,6 \mathrm{~b}$ & $95 \mathrm{a}$ & $6 \mathrm{a}$ \\
\hline CV (\%) & 8,2 & 2,5 & 3,7 & 6,6 & 14,0 & 2,9 & 9,8 \\
\hline
\end{tabular}

"Médias seguidas da mesma letra na coluna não diferem entre si pelo teste de Tukey ( $\leq \leq 0,05)$. TA: teor de água; PMS: peso de mil sementes; G: germinação; CTP: comprimento total de plântulas; CE: condutividade elétrica; E: emergência em bandejas e IVE: índice de velocidade de emergência.

Quanto ao peso de mil sementes (PMS) a cv. Hyola 61 obteve valor inferior às demais, diferindo significativamente do Hyola 60 e Hyola 401 (Tabela 1). A avaliação do PMS apresenta um indicativo do tamanho das sementes, como também do estado de maturidade e sanidade (BRASIL, 2009). Sementes maiores apresentam maiores quantidades de reservas e embriões bem formados e por isso podem apresentar altas porcentagens de germinação e vigor (BARBOSA et al., 2010).

As maiores porcentagens de germinação foram encontradas nas cultivares Hyola 61 e Hyola 60, diferindo significativamente do Hyola 401. O teste de germinação é conduzido em condições favoráveis, permitindo que as sementes expressem a máxima germinação (BRASIL, 2009) e, geralmente, superestima o potencial de desempenho das sementes a campo, tornando-se necessária a realização de outros testes para a complementação destas informações, através de procedimentos capazes de detectar possíveis diferenças no desempenho de lotes, com germinação elevada ou semelhante (MARCOS FILHO, 2015).

As cultivares Hyola 60 e 61 apresentaram resultados superiores para comprimento de plântula, assim como já haviam apresentado na germinação, desta maneira, as sementes dessas cultivares apresentaram bom desempenho de plântulas, com melhor potencial germinativo em relação à cv. Hyola 401 (Tabela 1).

Para o teste de condutividade elétrica (CE) a cv. a Hyola 60 apresentou menor quantidade de solutos liberado ao meio, indicando como de maior vigor, em relação a cv. Hyola 61, porém, essas cultivares não diferiram significativamente de Hyola 401 . O princípio do teste baseia-se na integridade das membranas celulares das sementes, consequentemente, aquelas de baixo vigor apresentam uma maior lixiviação de solutos representado pela maior condutividade elétrica como é o observado na cv. Hyola 61.

Em relação à emergência (E) não foram observadas diferenças significativas entre as cultivares (Tabela 1), no entanto, observa-se alta porcentagem de plântulas emergidas, indicando que as sementes dessas cultivares de canola apresentam um bom estande de plântulas no campo.

A cv. Hyola 60 foi superior às demais cultivares para variável índice de velocidade de emergência (IVE) (Tabela 1), consequentemente, mais vigorosa e evidenciando assim, uma melhor qualidade dessas sementes, quanto maior o valor obtido, maior é a velocidade de emergência, 
menos dias são os gastos para o processo de germinação (KRZYZANOWSKI et al., 1999).

O coeficiente de correlação entre os resultados de qualidade fisiológica indicam correlação positiva e significativa para o teste de teor de água (TA) e o peso de mil sementes (PMS); o PMS com germinação (G) e o comprimento total de plântulas (CTP); e também
G com CTP e o IVE (Tabela 2). Esses resultados indicam que as sementes de canola com maior peso, geram plântulas com maior taxa de crescimento e com melhor germinação, e que sementes que apresentam melhor germinação resultarão em um maior IVE e com maiores comprimentos totais de plântulas (Tabela 2).

Tabela 2. Coeficiente de correlação ( $r$ ) entre resultados de qualidade fisiológica de sementes de canola das cultivares Hyola 401, Hyola 61 e Hyola 60, safra 2012, cultivadas em Santa Maria, RS

\begin{tabular}{lllllll}
\hline & PMS (g) & $\mathrm{G}(\%)$ & $\mathrm{CTP}(\mathrm{cm})$ & $\mathrm{CE}\left(\mu \mathrm{cm}^{-1} \mathrm{~g}^{-1}\right)$ & $\mathrm{E}(\%)$ & $\mathrm{IVE}$ \\
\hline TA $(\%)$ & $0,45^{*}$ & $0,40^{\text {ns }}$ & $0,10^{\text {ns }}$ & $0,31^{\text {ns }}$ & $0,15^{\text {ns }}$ & $-0,25^{\text {ns }}$ \\
PMS (g) & & $0,73^{*}$ & $0,75^{*}$ & $0,24^{\text {ns }}$ & $0,25^{\text {ns }}$ & $0,36^{\text {ns }}$ \\
G $(\%)$ & & & $0,64^{*}$ & $-0,03^{\text {ns }}$ & $-0,09^{\text {ns }}$ & $0,15^{\text {ns }}$ \\
CTP $(\mathrm{cm})$ & & & & $0,01^{\text {ns }}$ & $0,15^{\text {ns }}$ & $0,66^{*}$ \\
CE $\left(\mu \mathrm{cm}^{-1} \mathrm{~g}^{-1}\right)$ & & & & & $-0,45^{*}$ & $0,29^{\text {ns }}$ \\
E (\%) & & & & & & $0,38^{\text {ns }}$ \\
\hline
\end{tabular}

${ }^{n s}$, r: não significativo; *, r: significativo $(p \leq 0,05)$. TA: teor de água; PMS: peso de mil sementes; G: germinação; CTP: comprimento total de plântulas; CE: condutividade elétrica; E: emergência em bandejas e IVE: índice de velocidade de emergência.

Segundo a AOSA (1983) para a interpretação do vigor de um lote, não deve-se considerar apenas resultados médios de comprimento da plântula, mas também os valores de germinação, pois alguns lotes podem apresentar por exemplo altas porcentagens de germinação e produzir plântulas de menor tamanho ou vice-versa. Vanzolini et al. (2007), trabalharam com lotes de sementes de soja, verificaram que o comprimento total das plântulas ou parte delas são sensível para classificar lotes com diferenças sutis de qualidade.

Verificou-se correlação negativa e significativa $(r=-0,45)$ entre 0 teste de condutividade elétrica e emergência (Tabela 2). Àvila et al. (2005), descrevem que o teste de emergência e condutividade elétrica apresentam sensibilidade em diferenciar a qualidade fisiológica de lotes de sementes de canola. Os resultados de vigor devem distinguir com segurança lotes com alto e baixo vigor e segundo Peske et al. (2012), esses testes devem apresentar correlação com a emergência a campo. Desta forma, sementes de canola que apresentam comprometimento da integridade do sistema de membranas tendem a apresentar menor capacidade das sementes em produzir plantas em campo (Tabela 1 e 2).

De acordo com o teste de sanidade, os fungos encontrados nas sementes foram: Alternaria alternata, A. brassicicola, A. japonica, Fusarium spp., P. lingam, Aspergillus flavus, Penicillium spp., Botrytis spp. e Rhizopus spp. (Tabela 3). Esses patógenos são comumente relatados em trabalhos com sementes de canola e sua incidência depende das condições climáticas durante o período de maturação e colheita, assim como os genótipos empregados (BRAZAUSKIENE; PETRAITIENE, 2006; JAJOR et al., 2012).

Tabela 3. Incidência (\%) de A. alternata (Aa), A. brassicicola (Ab), A. japônica (Aj), Fusarium spp. (F) $P$. lingam (P), A. flavus (A), Penicillium spp. (Pen), Botrytis spp. (B) e Rhizopus spp. (R) em sementes de canola das cultivares Hyola 401, Hyola 61 e Hyola 60, safra 2012, cultivadas em Santa Maria, RS

\begin{tabular}{lccccccccc}
\hline \multirow{2}{*}{ Tratamento } & \multicolumn{10}{c}{ Incidência de fungos (\%) } \\
\cline { 2 - 11 } & $\mathrm{Aa}$ & $\mathrm{Ab}$ & $\mathrm{Aj}$ & $\mathrm{F}$ & $\mathrm{P}$ & $\mathrm{A}$ & Pen & $\mathrm{B}$ & $\mathrm{R}$ \\
\hline Hyola 401 & $50,2 \mathrm{c}^{*}$ & $2,2 \mathrm{a}$ & $0,0^{\text {ns }}$ & $0,2^{\text {ns }}$ & $0,0^{\text {ns }}$ & $0,5^{\text {ns }}$ & $5,5 \mathrm{a}$ & $3,5 \mathrm{a}$ & $1,8^{\text {ns }}$ \\
Hyola 61 & $67,8 \mathrm{~b}$ & $0,5 \mathrm{~b}$ & 0,0 & 0,2 & 0,2 & 0,7 & $4,5 \mathrm{ab}$ & $1,2 \mathrm{~b}$ & 0,0 \\
Hyola 60 & $90,5 \mathrm{a}$ & $0,8 \mathrm{ab}$ & 0,3 & 0,0 & 0,2 & 0,7 & $2,7 \mathrm{~b}$ & $3,0 \mathrm{ab}$ & 0,0 \\
\hline Média & 69,5 & 1,2 & 0,1 & 0,1 & 0,1 & 0,6 & 4,2 & 2,6 & 0,6 \\
\hline CV (\%) & 8,7 & 34,4 & 24,2 & 27,3 & 27,3 & 45,8 & 44,4 & 43,4 & 71,9 \\
\hline
\end{tabular}


*Médias seguidas na mesma letra na coluna, não diferem entre si pelo teste de Tukey $(p \leq 0,05) .{ }^{\text {ns }}$ : não significativo.

A. alternata foi à espécie encontrada com maior média de incidência em todas as cultivares de canola, chegando a 90,5\% em sementes de Hyola 60, que diferiu significativamente dos demais, seguida por Hyola 61 e Hyola 401. Alguns trabalhos têm demonstrado a predominância de Alternaria spp. nessas sementes (ÁVILA et al., 2005; MARCHIORI JÚNIOR et al., 2002; MIGLIORINI et al., 2011) e a ocorrência desse patógeno em sementes pode causar prejuízos, visto que pode ser transmitido por elas para as plântulas (NEERGAARD, 1979). Além de causar, redução na germinação e tombamento de plântulas em pré ou pós-emergência (ROTEM, 1995), manchas foliares, queda prematura de folhas e síliquas (CARDOSO et al., 2005).

Diferenças significativas foram observadas entre as cultivares para incidência de A. brassicicola, com menor percentual para Hyola 61 o qual diferiu significativamente da cv. Hyola 401. Já para $A$. japônica, foi constatada a presença dessa espécie somente para a cv. Hyola 60 , no entanto sem diferença estatística (Tabela 3). Observa-se entre as cultivares que indecência média de $A$. brassicicola e $A$. japônica foram mais baixas em relação a $A$. alternata, demonstrando a predominância desse patógeno nas sementes dessa espécie.

Tohyama e Tsuda (1995), estudando lotes de sementes de diversas espécies de Brassica, constataram a presença de $A$. japonica, $A$. alternata e $A$. brassicicola. Segundo esses autores, as espécies patogênicas que causaram lesões necróticas nas plântulas foram a $A$. brassicicola e $A$. japônica, no entanto a $A$. alternata foi a mais frequente, porém considerado um patógeno oportunista, pois não desenvolveu sintomas em plântulas, sendo observado apenas algumas lesões claras nos cotilédones. Rude et al. (1999) verificaram que a qualidade fisiológica de sementes de canola foi afetada pela presença de Alternaria spp., entre as espécies a $A$. brassicae e $A$. raphani reduziram significativamente a germinação, enquanto que A. alternata não apresentou nenhum dano para as sementes.

Verificou-se ainda que os patógenos que ocorreram em menor incidência foram Penicillium spp., Botrytis spp., A. flavus, Rhizopus spp., Fusarium spp. e $P$. lingam, detectados em todas as cultivares, exceto Fusarium spp. no Hyola 60 e $P$. lingam em Hyola 401 (Tabela 3).
Alguns fatores podem interferir na infecção de patógenos nas sementes, como: genótipo, ambiente, práticas culturais, estágio de infecção na planta, severidade de infecção da planta mãe, infestação por insetos e manejo das sementes durante o beneficiamento (MACHADO, 2012).

Fungos do gênero Penicillium spp., $A$.

flavus e Rhizopus spp., são considerados saprófitas e, frequentemente estão presentes nas sementes, podendo causar deterioração das mesmas, principalmente quando armazenadas sob condições inadequadas, culminado com a perda da viabilidade e do valor comercial (CARVALHO; NAKAGAWA, 2012). Muniz et al. (2004), relataram que Aspergillus spp. interferem na qualidade fisiológica de sementes de melão. Menten (1995) observa que Rhizopus spp. causa podridões em sementes e plântulas de algodão em pré e pós-emergência. Fungos como Penicillium spp. e A. flavus também foram observados por Rosa et al. (2015) em diferentes cultivares de canola submetidas ou não ao tratamento químico.

$P$. lingam foi observado em baixa incidência nas sementes e apenas nas cultivares Hyola 61 e Hyola 60, no entanto sem diferença estatística significativa. A doença canela preta causada por esse patógeno é caracterizada por apresentar lesões foliares e cancros basais (CARDOSO et al., 2005). Quando detectada nas fases iniciais de desenvolvimento da cultura pode causar tombamento de plântulas. Para Szopińska et al. (2007), a associação de Phoma spp. ocorre ocasionalmente em sementes de canola e esse pode estar aderido tanto no tegumento como no embrião da semente, infectando cotilédones e radícula.

A incidência de Botrytis spp. variou de 1,2 à $3,5 \%$, respectivamente para as cultivares Hyola 61 e Hyola 401 diferindo-se significativamente. A presença desse fungo em sementes de grão de bico (Cicer arietinum L.) pode causar apodrecimento e posterior redução da germinação, consequentemente, afetando o estabelecimento de plântulas no campo (BURGESS et al.,1997). O mesmo tem sua incidência variável entre anos e encontra-se tanto internamente como externamente em sementes de canola (SZOPIŃSKA et al., 2007).

Segundo França Neto e Henning (1984), a incidência de patógenos nas sementes não significa necessariamente o comprometimento 
da germinação e origem de plântulas e plantas doentes. Assim, para complementar o teste de sanidade, o teste de transmissão torna-se importante para verificar se realmente as sementes contaminadas irão transmitir os patógenos para as plântulas e, em caso positivo, quais sintomas irão produzir (LAZAROTTO et al., 2012).

Foi observado no teste de transmissão, um percentual de plântulas normais acima de 92 $\%$, embora sem diferenças significativas entre as cultivares (Tabela 4). A cv. Hyola 60 apresentou menor porcentagem de sementes mortas, diferindo significativamente das demais, indicando assim, uma menor incidência de tombamento de plântulas de pré-emergência. No entanto, para plântulas sintomáticas (PS) essa cultivar, assim como a Hyola 61 obtiveram as maiores porcentagem, diferindo significativamente da cv. Hyola 401, a qual não foi observada sintomas em plântulas, somente em sementes não germinadas. Os sintomas observados em plântulas eram manchas escuras na região do colo seguido de tombamento. Esses resultados inferem que os sintomas podem aparecer tanto em pré como em pós-emergência para as cultivares Hyola 60 e Hyola 61.

Tabela 4. Plântulas normais (PN), sementes não germinadas (SNG), plântulas sintomáticas (PS) e percentuais (\%) de fungos identificados no teste de transmissão por sementes de canola das cultivares Hyola 401, Hyola 61 e Hyola 60, safra 2012, cultivadas em Santa Maria, RS

\begin{tabular}{lllllllll}
\hline \multirow{2}{*}{ Tratamento } & \multicolumn{3}{c}{$(\%)$} & & \multicolumn{3}{c}{ Incidência de fungos em PS (\%) } \\
\cline { 2 - 4 } \cline { 7 - 9 } & PN & SNG & PS & & P. lingam & A. alternata & A. brassicicola \\
\hline Hyola 401 & $94^{\text {ns }}$ & $6 \mathrm{a}^{*}$ & $0 \mathrm{~b}$ & & $0,0^{\text {ns }}$ & & $0,0 \mathrm{~b}$ & $0,0 \mathrm{~b}$ \\
Hyola 61 & 92 & $5 \mathrm{a}$ & $3 \mathrm{a}$ & & 0,0 & & $1,7 \mathrm{ab}$ & $1,0 \mathrm{a}$ \\
Hyola 60 & 95 & $1 \mathrm{~b}$ & $4 \mathrm{a}$ & & 0,3 & & $3,4 \mathrm{a}$ & $0,3 \mathrm{ab}$ \\
\hline Média & 94 & 4 & 2 & & 0,11 & & 1,7 & 0,44 \\
\hline
\end{tabular}

${ }^{*}$ Médias seguidas pela mesma letra na coluna, não diferem entre si pelo teste de Tukey $(p \leq 0,05) .{ }^{\text {ns }}$ : não significativo.

Os fungos associados aos sintomas nas plântulas de canola foram P. lingam, A. alternata e A. brassicicola (Tabela 4). Somente estes foram transmitidos via semente para as plântulas e, apenas a transmissão de $A$. alternata $e$. brassicicola apresentaram diferenças significativas entre as cultivares.

A transmissão de $P$. lingam foi verificado somente para o Hyola 60 e em baixas porcentagens $(0,3 \%)$, confirmando a afirmação de Cardoso et al. (2005) pela baixa transmissão deste fungo das sementes para as plântulas.

Entre as cultivares, a maior incidência de A. alternata nas plântulas foi verificada na cv. $\begin{array}{llllll}\text { Hyola } & 60 & (3,4 & \%) & \text { e não diferindo }\end{array}$ significativamente de Hyola 61 (1,7 \%) (Tabela 4). Enquanto que para $A$. brassicicola a maior incidência foi verificada na cv. Hyola 61 (1\%), não diferindo da Hyola 60 (0,3\%). Sementes mais contaminadas (Tabela 1) podem apresentar uma maior incidência em plântulas sintomáticas (Tabela 2). No entanto, para a cv. Hyola 401 foi possível observar que os danos foram em préemergente, ou seja, antes mesmo de ocorrer à emergência, podendo haver uma maior suscetibilidade dos fungos quando associados às sementes em causar morte nessa cultivar.
Corroborando com o presente trabalho, a ocorrência de Alternaria spp. em sementes e a sua transmissão para as plântulas, já foi verificada por Seidle et al. (1995) em canola (Brassica napus L.), Verzignassi et al. (1997) em estévia (Stevia rebaudiana) Moraes e Menten (2006) em feijão (Phaseolus vulgaris L.), Nery et al. (2009) em sementes de nabo forrageiro (Raphanus sativus L. var. oleiferus); Lazarotto et al. (2010) em paineira (Ceiba speciosa) e Ismail et al. (2012) em couve flor (Brassica oleracea var. botrytis). Esses autores ainda afirmam que as diferentes espécies desse gênero reduzem a qualidade das sementes, causam necrose em plântulas e tombamento em pré e pósemergência.

\section{CONCLUSÕES}

As avaliações de germinação, comprimento total de plântulas, condutividade elétrica e IVE permitem a diferenciação das cultivares de sementes de canola.

Fungos como A. alternata, A. brassicicola, A. japonica, Fusarium spp., $P$. lingam, A. flavus, Penicillium spp., Botrytis spp. e Rhizopus spp. estão presentes nas sementes de canola. 
A. alternata, A. brassicicola e $P$. lingam são transmitidos para as plântulas de canola quando associados às suas sementes, causando lesões necróticas na região do colo, tombamento de plântulas e morte das sementes.

\section{REFERÊNCIAS}

AOSA. Seed vigor testing hand book. Nova York: AOSA, 1983. (Contribution; 32).

ARAÚJO, E. R. Qualidade fisiológica, etiologia e patogenicidade de fungos assinalados em sementes de aroeira produzidas em três municípios da Paraíba. 2008. 45 f. Dissertação (Mestrado) - Universidade Federal da Paraíba, Areia-PB, 2008.

ÁVILA, M. R.; BRACCINI, A. L.; SCAPIM, C. A.; MARTORELLI, D. T.; ALBRECHT, L. P. Testes de laboratório em sementes de canola e a correlação com a emergência das plântulas em campo. Revista Brasileira de Sementes, v. 27, p. 62-70, 2005. http://dx.doi.org/10.1590/S010131222005000100008.

BARNETT, H. L.; HUNTER, B. B. Illustrated genera of imperfect fungi. St Paul, Minnesota: APS Press, 1998.

BARBOSA, C. Z. R.; SMIDERLE, O. J.; ALVES, J. M. A.; VILARINHO, T. S. Qualidade de sementes de soja BRS Tracajá, colhidas em Roraima em função do tamanho no armazenamento. Revista Ciência Agronômica, v.41, p. 73-80, 2010.

BRASIL. Regras para análise de sementes. Brasília: Mapa/ACS, 2009.

BRAZAUSKIENE, I.; PETRAITIENE, E. The occurrence of Alternaria blight (Alternaria spp.) and Phoma stem canker (Phoma lingam) on oilseed rape in Central Lithuania and pathogenic fungi on harvested seed. Journal of Plant Protection Research, v. 46, p. 295-311, 2006.

BURGESS, D. R.; BRETAG, T. W.; KEANE, P. J. Seedto-seedling transmission of Botrytis cinerea in chickpea and disinfestation of seed with moist heat. Animal Production Science, v.37, p.223-229, 1997. http://dx.doi.org/10.1071/EA96061

CARDOSO, R. M. L.; LEITE, R. M. V. B. C.; BARBOSA, C. J. Doenças de canola (Brassica napus e $B$. campestris). In: KIMATI, $\mathrm{H}$. et al.
Manual de Fitopatologia. 4. ed. São Paulo: Agronômica Ceres, 2005. p.197-208.

CARVALHO, N. M.; NAKAGAWA, J. Sementes: ciência, tecnologia e produção. Jaboticabal: FUNEP, 2012.

EMBRAPA. Centro Nacional de Pesquisa de Solos. Sistema Brasileiro de Classificação de solos. Rio de Janeiro: Embrapa Solos, 1999.

ESTEVEZ, R. L.; DUARTE, J. B.; CHAMBO, A. P. S.; CRUZ, M. I. F. DA. A cultura da canola (Brassica napus var. oleifera). Scientia Agraria Paranaensis, v. $13, \quad$ n. $1, \quad$ p. 1-9, 2014. http://dx.doi.org/10.1818/sap.v13i1.8177

FRANÇA NETO, J. B.; HENNING, A. A. Qualidade fisiológica e sanitária de sementes de soja. Londrina: EMBRAPA-CNPSo, 1984.

HELDWEIN, A. B.; BURIOL, G. A.; STRECK, N. A. O clima de Santa Maria. Ciência \& Ambiente, v. 38, n. 1, p. 43-58, 2009.

ISMAIL, M.; ANWAR, S. A.; IQBAL, A.; AHMAD, N.; ARAIN, M. A. Seed-borne fungi associated with cauliflower seeds and their role in seed germination. Pakistan Journal of Phytopathology, v. 24, n. 1, p. 26-31, 2012. doi: 10.1007/BF02814730.

JAJOR, E.; KOZŁOWSKA, M.; WÓJTOWICZ, M. Prevalence of fungi of the genus Alternaria on rape siliques and seeds depending on weather conditions. Progress in Plant Protection, v. 52, n. 4, p. 1011-1015, 2012. http://dx.doi.org/10.14199/ppp-2012-174.

KRZYZANOWSKI, F. C.; VIEIRA, R. D.; FRANÇA NETO, J. Vigor de sementes: conceitos e testes. Londrina: ABRATES, 1999.

LAZAROTTO, M.; MUNIZ, M. F. B.; SANTOS, A. F. Detecção, transmissão, patogenicidade e controle químico de fungos em sementes de paineira (Ceiba speciosa). Summa Phytopathologica, v. 36 , n. 2, p. 134-139, 2010. http://dx.doi.org/10.1590/S0100$\underline{54052010000200005 .}$.

LAZAROTTO, M.; MUNIZ, M. F. B.; BELTRAME, R.; SANTOS, A. F.; MACIEL, C. G.; LONGHI, S. J. Sanidade, transmissão via semente e 
patogenicidade de fungos em sementes de Cedrela fissilis procedentes da região sul do Brasil. Ciência Florestal, v. 22, n. 3, p. 493-503, 2012. http://dx.doi.org/10.5902/198050986617.

MACHADO, J. C. Patologia de sementes: fundamentos e aplicações. Brasília: ESAL: FAEPE, 1988.

MACHADO, J. C. Tratamento de sementes no controle de doenças. Lavras: LAPS/UFLA/FAEPE, 2000 .

MACHADO, J. C. Patologia de sementes: significado e atribuições. In: CARVALHO, N. M.; NAKAGAWA, J. Sementes: ciência, tecnologia e produção. Jaboticabal: FUNEP, 2012. p. 524-590.

MARCOS FILHO, J. Fisiologia de sementes de plantas cultivadas. Londrina: ABRATES, 2015.

MAGUIRE, J. D. Spead of germination-aid in selection and evaluation for seedling emergence and vigour. Crop Science, v. 2, p. 176-177, 1962.

MARCHIORI JR., O.; INOUE, M. H.; BRACCINI, A. L.; OLIVEIRA JR., R. S.; AVILA, M. R.; LAWDER, M.; CONSTANTIN, J. Qualidade e produtividade de sementes de canola (Brassica napus) após aplicação de dessecantes em pré-colheita. Planta Daninha, v. 20, n. 2, p. 253-261, 2002. https://dx.doi.org/10.1590/S0100-

83582002000200012

MARINO, R. H.; MESQUITA, J. B.; ANDRADE, K. V. S.; COSTA, N. A.; AMARAL, L. A. Incidência de fungos em sementes de Phaseolus vulgaris $\mathrm{L}$. provenientes do Estado de Sergipe. Revista Brasileira de Ciências Agrárias, v.3, n.1, p.26-30, 2008.

http://dx.doi.org/10.5039/agraria.v3i1a289.

MENTEN, J. O. M. Patógenos em sementes: detecção, danos e controle químico. São Paulo: Ciba Agro, 1995.

MIGLIORINI, P.; KULCZYNSKI, S. M.; SANGIOGO, M.; KOCH, F.; BELLE, C.; SOMAVILLA, L. Incidência e manejo de doenças em cultivares de canola (Brassica napus L. e Brassica rapa L.) produzidas na região Norte do Rio Grande do Sul. In: JORNADA ACADÊMICA INTEGRADA, 26., JAI, Santa Maria. Anais... Santa Maria: UFSM, 2011.
MORAES, M. H. D.; MENTEN, J. O. M. Transmissão de Alternaria spp. através de sementes de feijão e seu efeito sobre a qualidade fisiológica das sementes. Summa Phytopathologica, v.32, p.381-383, 2006.

http://dx.doi.org/10.1590/S0100-

$\underline{54052006000400012 .}$

MUNIZ, M. F. B.; GONÇALVES, N.; GARCIA, D. C.; KULCZYNSKI, S. M. Comparação entre métodos para avaliação da qualidade fisiológica e sanitária de sementes de melão. Revista Brasileira de Sementes, v. 26, n.2, p. 144-149, 2004. http://dx.doi.org/10.1590/S010131222004000200020.

NEERGAARD, P. Seed pathology. London: Mc Millan Press, 1979.

NERY, M. C.; CARVALHO, M. L. M.; GUIMARÃES, R.M. Testes de vigor para avaliação da qualidade de sementes de nabo forrageiro. Informativo Abrates, v.19, n.1, p. 9-20, 2009.

PESKE, S. T.; VILLELA, F. A.; Meneghello, G. E. Sementes: Fundamentos científicos e tecnológicos. Pelotas: Editora e gráfica universitária. 2012.

POWELL, A. A.; MATTHEWS, S. The damaging effect of water of dry pea embryos during imbibition. Journal of Experimental Botany, v.29, n. $\quad 5, \quad$ p. $1215-1229,1978$. https://doi.org/10.1093/jxb/29.5.1215

ROSA, H. H. R.; DE ARAÚJO, D. V.; BAGATINI, G. J.; AMBRÓSIO, J.; DIAS, L. D. E.; SERRA-BRASIL, G. T. Eficiência do tratamento químico de sementes na germinação, vigor e sanidade em diferentes cultivares de canola. Enciclopédia Biosfera, v. 11, n.21, p. 956-966, 2015.

ROTEM, J. The genus Alternaria. St. Paul: APS Press, 1995.

RUDE, S. V.; DUCZEK, L. J.; SEIDLE, E. The effect of Alternaria brassicae, Alternaria raphani and Alternaria alternata on seed germination of Brassica rapa canola. Seed Science and Technology, v. 27, n. 2, p. 795-798, 1999.

SANTOS, A.; SCALON, S. P. Q.; MASETTO, T. E.; NUNES, D. P. Disponibilidades hídricas do substrato na qualidade fisiológica de sementes de 
canola com diferentes teores de água. Agrarian, v. 5, n. 18, p. 356-364, 2012.

SEIDLE, E.; RUDE, S.; PETRIE, A. The effect of Alternaria black spot of canola on seed quality and seed yield, and studies on disease control. Canada: Agriculture and Agri-Food Canada Saskatoon, 1995.

SIMMONS, E. G. Alternaria: an identification manual. Netherlands: CBS Fungal Biodiversity Centre, 2007.

SZOPIŃSKA, D.; TYLKOWSKA, K.; STACH, A. Relationships between seed development stage, germination, occurrence and location of fungi in oilseed rape (Brassica napus spp. oleifera L.) seeds and the presence of Alternaria and Cladosporium spp. spores in the air. Electronic Journal of Polish Agricultural Universities, v. 10, n. 4, p. 19-20, 2007.

TOHYAMA, A.; TSUDA, M. Alternaria on cruciferous plants. 4. Alternaria species on seed of some cruciferous crops and their pathogenicity. Mycoscience, v. 36, p. 257-261, 1995. Doi: 10.1007/BF02268599.

TOMM, G. O.; WIETHÖLTER, S.; DALMAGO, G. A.; SANTOS, H.P. Tecnologia para produção de canola no Rio Grande do Sul. Passo Fundo: Embrapa Trigo, 2009. 88 p. (Documentos; 92).

VERZIGNASSI, J. R.; VIDA, J. B.; HOMECHIN, M. Ocorrência e transmissão de Alternaria steviae e A. alternata em sementes de Stevia rebaudiana (Bert.) Bertoni. Revista Brasileira de Sementes, v. 19, n. 2, p. 283-287, 1997.

http://dx.doi.org/10.17801/0101-

3122/rbs.v19n2p283-287

VANZOLINI, S.; ARAKI, C. A. S.; SILVA, A. C. T. M.; NAKAGAWA, J. Teste de comprimento de plântula na avaliação da qualidade fisiológica de sementes de soja. Revista Brasileira de Sementes, v. 29, n. 2, p. 90-96, 2007. http://dx.doi.org/10.1590/S0101-

31222007000200012.
Recebido para publicação em 30/08/2017 Revisado em22/10/2017

Aceito em 18/11/2017 